\title{
Estudos culturais e estudos descoloniais: diálogos e rupturas na construção de uma pesquisa de recepção
}

\section{Fernanda Nascimento}

Jornalista, mestra em Comunicação Social pela Pontifícia Universidade Católica do Rio Grande do Sul (PUCRS), doutoranda no Programa Interdisciplinar em Ciências Humanas pela Universidade Federal de Santa Catarina (UFSC), na área de Estudos de Gênero.

E-mail:fn.imprensa@gmail.com
Resumo: Este artigo discute a possibilidade de construção de uma pesquisa de recepção por meio da articulação entre os estudos culturais e os estudos descoloniais. A partir da constatação de que os estudos de recepção estão intrinsecamente relacionados aos estudos culturais e que esta última tradição de estudos tem recebido críticas por autores descoloniais, propõe-se a construção de uma pesquisa de recepção inspirada nos estudos descoloniais.

Palavras-chave: Estudos de recepção; Estudos culturais; Estudos descoloniais; Comunicação social.

Cultural studies and descolonial studies: dialogues and ruptures in the construction of a reception research

Abstract: This article discusses the possibilitie of building a reception research with use of articulation between cultural studies and decolonial studies. Based on the fact that reception studies are intrinsically related to cultural studies, and that the latter has received criticism by decolonial authors, this study proposes the creation of a reception research inspired by decolonial studies.

Keywords: Reception studies; Cultural studies; Decolonial studies; Social communication. 


\title{
Introdução
}

Este artigo propõe a reflexão sobre a possibilidade de diálogo entre duas das principais vertentes intelectuais latino-americanas: os estudos culturais e os estudos descoloniais. A iniciativa tem como objetivo refletir a respeito da possibilidade de construção de uma pesquisa de recepção - cuja tradição está ligada ao projeto dos estudos culturais latino-americano - com base nas contribuições de teóricos da descolonialidade. Entre os desafios discutidos estão os limites de diálogo dos estudos descoloniais com outras propostas teóricas.

A problematização surge a partir de algumas das grandes questões que acompanham os estudos descoloniais, conforme Luciana Ballestrin (2013: 112):

\begin{abstract}
...As grandes questões a serem colocadas para o grupo seriam: é possível romper com a lógica da colonialidade da modernidade sem que abandonemos as contribuições do pensamento ocidental/europeu/iluminista - especialmente, liberalismo e marxismo - para a própria decolonização? Será que o êxito da sua proposta depende de sua própria condição subalterna e periférica? Qual o limite da implosão sobre a base epistemológica das ciências sociais? Será que, ao enfatizar superações e ao negar as influências do pós-estruturalismo, pós-marxismo e pós-colonialismo, o grupo não estaria criando uma nova hybris del punto cero? Como lidar com a paternidade europeia das nossas instituições e pensamentos políticos? Como verificar empiricamente hoje o sujeito colonizado? Experiências consideradas decoloniais, como o novo constitucionalismo latino-americano andino, por exemplo, estariam então livres de contradições? Devem-se decolonizar as instituições políticas - ou quais seriam as instituições políticas decoloniais? Como operacionalizar metodologicamente a análise das escalas, níveis, esferas que a colonialidade perpassa? Os movimentos sociais atuais, em seus discursos e práticas, identificam a colonialidade e reivindicam a decolonização?
\end{abstract}

\footnotetext{
${ }^{1}$ Mignolo analisa que o trabalho dos dois principais teóricos da recepção na América Latina, Nestor Garcia Canclini e Jesús Martín-Barbero, foi muito influenciado pelas obras de Pierre Bourdieu e da Escola de Frankfurt, respectivamente. Para o autor, ambos trabalham dentro da perspectiva da modernidade. Mignolo exemplifica seu argumento ao afirmar que "García-Canclini, por exemplo, estudou a fronteira, em Tijuana. Sua epistemologia, no entanto, não foi infectada pela fronteira. Permaneceu com a arrogância do ponto zero"(MIGNOLO, 2007: 165, tradução nossa).
}

Se, por um lado, Walter Mignolo (2007), expoente dos estudos descoloniais, classifica os estudos culturais como "imperialistas" e defende a ruptura epistemológica como principal diferencial entre os dois ${ }^{1}$, por outro, Jesús Martín-Barbero (1996: 52) reivindica uma tradição única para os estudos culturais produzidos a partir da América Latina: "a América Latina não se incorporou aos Estudos Culturais quando a etiqueta virou moda; a história, aqui, é muito distinta".

Para debater essa problemática, este artigo está estruturado em três partes. Em um primeiro momento, discutem-se as origens, características e debates apresentados pelos estudos descoloniais. Posteriormente, são discutidos estudos culturais e características dos estudos de recepção inseridos nessa tradição de pesquisa. Por fim, são apresentadas considerações acerca das possibilidades de diálogo entre as duas concepções teóricas.

\section{Estudos descoloniais}

Ao realizar a genealogia dos estudos descoloniais, Ballestrin (2013) identifica que o seu surgimento está ligado a uma tradição crítica de pensamento latino-americano. Os estudos descoloniais são sucessores e se desenrolaram a partir das contribuições dos estudos pós-coloniais e culturais - que repensam as construções da diferença colonial, posicionando-a ao lado dos colonizados e, ao mesmo tempo, reivindicam uma ruptura com esses movimentos compreendidos como "imperialistas" pela continuidade na perspectiva de análise a partir das ideias de autores eurocêntricos. O pensamento descolonial é político e "comprometido com a superação das relações de colonização, colonialismo e colonialidade" (BALLESTRIN, 2013: 91).

Pensadores descoloniais reivindicam uma diferenciação entre estudos pós-coloniais e estudos culturais pela compreensão de que a colonialidade persiste ainda que os regimes coloniais de invasão dos territórios americanos tenham sido formalmente 


\author{
${ }^{2}$ Ballestrin (2013) destaca que um dos \\ desafios da descolonialidade é pensar \\ para além das Américas espanhola \\ e portuguesa. Acrescenta-se a \\ necessidade de pensar a América Latina \\ como território composto também \\ por ex-colônias francesas, inglesas e \\ holandesas, como Suriname, Guiana \\ Francesa e Antilhas. Inclusive há a \\ necessidade de destacar a persistência \\ da colonialidade instituída formalmente, \\ como no caso da Guiana Francesa, \\ considerada até a atualidade um \\ departamento ultramarino francês.
}

extintos com a proclamação de independência da maioria dos países da América do Sul e América Central, ao longo dos séculos XVIII, XIX e XX².

Um dos mais poderosos mitos do século XX foi a noção de que a eliminação das
administrações coloniais conduzia à descolonização do mundo, o que originou o
mito de um mundo "pós-colonial". As múltiplas e heterogêneas estruturas globais,
implantadas durante um período de 450 anos, não se evaporaram juntamente
com a descolonização jurídico-política da periferia ao longo dos últimos 50
anos. Continuamos a viver sob a mesma "matriz de poder colonial". Com a
descolonização jurídico-política saímos de um período de "colonialismo global"
para entrar num período de "colonialidade global". (GROSFOGUEL, 2008: 117)

Entre os principais conceitos que integram o pensamento descolonial está o de "colonialidade de poder". Desenvolvido por Aníbal Quijano, o pressuposto defende que as relações de colonialidade não se findaram com a destituição do colonialismo. Quijano analisa que raça, gênero e trabalho são categorias centrais, segundo as quais o capitalismo se organizou, presentes no discurso que embasa a modernidade e a colonialidade a partir do século XVI.

À "colonialidade do poder" articula-se também o conceito de "colonialidade do saber", associado à ideia de "diferença colonial e geopolítica do conhecimento" conceitos que embasam a crítica e proposta de ruptura do pensamento descolonial com o pensamento eurocêntrico. "O esforço [...] não é uma mera questão de verdade histórica, mas de categorias geoculturais e suas relações com o conhecimento e poder" (MIGNOLO, 2002: 847, tradução nossa) ${ }^{3}$.

Pensar a América Latina a partir da América Latina e com autores e teorias latinoamericanas é uma das premissas do grupo descolonial ${ }^{4}$. A importância disso está na reflexão e problematização sobre a objetividade e neutralidade da forma de pensamento, impostas pelo conhecimento científico eurocêntrico e tomadas como ponto de partida para a análise de qualquer população e realidade.

isto permitiu ao homem ocidental (esta referência ao sexo masculino é usada intencionalmente) representar o seu conhecimento como o único capaz de alcançar uma consciência universal, bem como dispensar o conhecimento não ocidental por ser particularístico e, portanto, incapaz de alcançar a universalidade. (GROSFOGUEL, 2008: 124)

o nome de Abya Yala, vocábulo da língua kuna, vem se tornando corrente para nomear toda a América e, em especial, a América Latina e a América Central. O vocábulo significa "terra de vida" ou "terra madura" e foi escolhido por povos originários como forma de reconhecimento ao pioneirismo dos kuna na conquista de sua autonomia territorial, em 1930, no arquipélago de San Blas, Panamá (LISBOA, 2014).
O essencial aqui é o locus da enunciação, ou seja, o lugar geopolítico e corpopolítico do sujeito que fala. Na filosofia e nas ciências ocidentais, aquele que fala está sempre escondido, oculto, apagado da análise. A "egopolítica do conhecimento" da filosofia ocidental sempre privilegiou o mito de um "Ego" não situado. O lugar epistêmico étnico-racial/sexual/de gênero e o sujeito enunciador encontram-se, sempre, desvinculados. Ao quebrar a ligação entre o sujeito da enunciação e o lugar epistêmico étnico-racial/sexual/de gênero, a filosofia e as ciências ocidentais conseguem gerar um mito sobre um conhecimento universal Verdadeiro que encobre, isto é, que oculta não só aquele que fala como também o lugar epistêmico geopolítico e corpo-político das estruturas de poder/conhecimento colonial, a partir do qual o sujeito se pronuncia. (Ibid.: 122) 
Indígenas de Abya Yala - os estudos descoloniais podem ser descritos como "o movimento de resistência teórico e prático, político e epistemológico, à lógica da modernidade/colonialidade" (BALLESTRIN, 2013: 105). Entre os autores que integram o grupo é possível citar como referências Walter Mignolo, Enrique Dussel, Nelson Maldonado Torres, Aníbal Quijano e Ramón Grosfoguel. No feminismo descolonial, destacam-se María Lugones e Yuderkys Espinosa Miñoso.

As principais críticas recebidas pelo grupo são de que os autores dialogam "de uma maneira seletiva com nomes clássicos" (BALLESTRIN, 2013: 110), usando alguns autores das ciências sociais e da filosofia do Ocidente sem compreender o contexto de construção do conhecimento. Alguns desses questionamentos serão retomados nas próximas seções, com a discussão sobre a possibilidade de aproximação entre os estudos descoloniais e os estudos culturais.

\section{Estudos culturais e estudos de recepção}

A relação da audiência com os produtos da cultura da mídia desperta o interesse das mais diversas áreas do conhecimento. Na comunicação social, local de maior concentração dessas pesquisas, a preocupação com essa problemática se iniciou com as chamadas pesquisas dos efeitos ${ }^{5}$, passando pelos estudos de usos e gratificações ${ }^{6}$

${ }^{5}$ Teoria ligada à tradição funcionalista norte-americana, datada da década de 1940. Rompe com a proposta da teoria hipodérmica, de que a comunicação é formada de maneira linear por emissormensagem-receptor, ao pesquisar os "efeitos" dos meios de comunicação, junto aos expectadores. "Os estudos dos efeitos são aqueles que apresentam em comum a preocupação em entender quais são e como se produzem os efeitos dos media sobre seus receptores" (GOMES, 2004: 31).

${ }^{6}$ Produzida a partir da década de 1950, também de origem funcionalista, é a primeira perspectiva teórica a reconhecer o público como agente ativo, o que "implicava supor que o uso dos meios era dirigido por objetivos claros e conscientes, no caso, a satisfação de necessidades psicológicas individuais" (Ibid.: 40).

\footnotetext{
${ }^{7}$ No original: "Los estudios culturales se han estandarizado como una alternativa a (o una subsunción de) las disciplinas académicas de la sociología, la antropología, las ciencias de la comunicación y la crítica literaria, en el marco general de la condición posmoderna. El ámbito preferencial de los estudios es la cultura popular" (REYNOSO, 2000: 3).
} e, atualmente, sendo produzida prioritariamente pelos estudos de recepção.

A vinculação entre estudos de recepção e estudos culturais é intrínseca, iniciandose com a publicação do texto "Codificação e decodificação", nos anos 1970, por Stuart Hall - um dos cânones dos estudos culturais britânicos e das pesquisas diaspóricas. Nessa obra seminal, Hall (2013) enfatiza a possibilidade de negociação na esfera da recepção, sinalizando para três posições que podem ser adotadas pelos receptores diante das mensagens: dominante, quando o sentido da mensagem é decodificado segundo as referências de sua construção; negociada, quando receptores negociam os sentidos das mensagens; ou de oposição, quando se rejeita a mensagem.

Ao longo dos anos, diferentes vertentes de estudo foram criadas e interessa a este texto a abordagem dos estudos de recepção produzidos a partir da perspectiva dos estudos culturais latino-americanos. Para Itania Maria Mota Gomes (2004: 29) não há distinção entre as análises de recepção e os estudos culturais:

Recusamos a distinção entre as análises de recepção e os estudos culturais porque entendemos que, rigorosamente, as análises de recepção são as investigações empíricas sobre a relação entre media e audiência realizadas dentro do quadro teórico-metodológico dos Estudos Culturais.

Nesse sentido, todas as produções no âmbito da recepção seriam geradas dentro desse marco teórico-metodológico. O posicionamento não é consenso, Ana Carolina D. Escosteguy e Nilda Jacks (2005), mapearam as pesquisas de recepção produzidas no país nos anos 1990 . Ainda que $73 \%$ delas tenham sido categorizadas como pesquisas de cunho "sociocultural", ligadas à tradição dos estudos culturais, existem $27 \%$ das pesquisas identificadas pelas autoras como estudos de recepção, mas realizadas nos marcos das discussões "comportamentais" das pesquisas de efeitos e de usos e gratificações.

Ao abordar as pesquisas de recepção é necessário pensar sobre a tradição à qual estão relacionadas, a saber, os estudos culturais. Definir o que são os estudos culturais é tarefa considerada difícil, quando não, desnecessária. Mais do que a definição de conjunto de saberes, teorias e metodologias limitadas, os estudos culturais transformaram-se em um espaço de discussão alternativo aos "estudos das disciplinas acadêmicas de sociologia, antropologia, ciências da comunicação e da crítica literária, em um marco geral da condição pós-moderna. O âmbito preferencial dos estudos sobre a cultura popular" (REYNOSO, 2000: 3 , tradução nossa) ${ }^{7}$. Nas palavras de Marisa Vorraber Costa, Rosa Hessel Silveira 
e Luis Henrique Sommer (2003: 39), esses estudos podem ser compreendidos como um "tumulto teórico":

\begin{abstract}
Os Estudos Culturais não constituem um conjunto articulado de ideias e pensamento. Como dizem seus cronistas mais contundentes, eles são e sempre foram um conjunto de formações instáveis e descentradas. Há tantos itinerários de pesquisa e tão diferentes posições teóricas que eles poderiam ser descritos como um tumulto teórico.
\end{abstract}

Emergentes no fim da década de 1950, na Inglaterra, os estudos culturais têm entre as suas principais temáticas de análise: gênero e sexualidades; raça, etnicidades e representações culturais; estudos históricos; e cultura popular e cultura nacional. Entre seus principais campos de estudo estão a mídia, a educação e a cultura popular em suas mais diversas manifestações.

No que se refere aos estudos culturais latino-americanos, há uma reivindicação dos principais teóricos do campo quanto à sua especificidade. Jesús Martín-Barbero (1996) sustenta que a tradição de estudos culturais existia na América Latina antes da criação dessa terminologia, ou seja, desvincula essa corrente de pensamento da possibilidade de "importação de teorias" do hemisfério Norte, especialmente da Inglaterra.

Nós fazíamos Estudos Culturais há muito tempo. Na América Latina - no campo da Comunicação, desde a edição do livro de Pascuali nos anos sessenta - havia uma percepção de que os processos de comunicação eram processos culturais. [...] Não comecei a falar de cultura porque chegaram a mim coisas de fora. Foi lendo Martí, Arguedas que eu a descobri e, com ela, os processos de comunicação a serem analisados. A gente não se ocupava dos meios: estávamos na festa, na casa, na cantina, no estádio. [...] Fazíamos Estudos Culturais muito antes que esta etiqueta aparecesse [...] A América Latina não se incorporou aos Estudos Culturais quando a etiqueta virou moda; a história, aqui, é muito distinta. (MARTíNBARBERO, 1996: 52)

A categorização é difícil e para Eduardo Restepro (2015), é uma "meia-verdade", na medida em que estudos sobre cultura não podem ser considerados estudos culturais e, evidentemente, grande parte da produção anterior está associada à essa discussão. Escosteguy (2010) sinaliza que apenas a partir dos anos 1990, autores da América Latina começam se identificar como integrantes dessa tradição de estudos. A resistência se daria em decorrência de que as afinidades poderiam descaracterizar a independência e autonomia da produção desenvolvida na região (ESCOSTEGUY, 2010: 46). Ainda que a identificação tenha sido tardia, a autora aponta para a construção dessas pesquisas em período anterior, iniciando-se nas décadas de 1970 e 1980, em diálogo com outras movimentações globais.

Levando em consideração esse pano de fundo, os estudos culturais questionam a produção de hierarquias sociais e políticas a partir de oposições entre tradição e inovação, entre a grande arte e as culturas populares, ou, então, entre níveis de cultura - por exemplo, alta e baixa, cultura de elite e cultura de massa. A consequência natural desse debate é a revisão dos cânones estéticos ou mesmo de identidades regionais e nacionais que se apresentam como universais ao negarem ou encobrirem determinações de raça, gênero e classe. (Ibid.: 47)

Para Héctor Gómez (2011), o desenvolvimento dessa vertente de estudos na América Latina aconteceu lentamente, por pesquisadores de diferentes países que criticavam a importação de teorias norte-americanas, aliado a um processo 
${ }^{8}$ No original: "en algún momento dentro de los estudios de la comunicación hubo un cambio al pasar de la pregunta ¿qué hacen los medios con la gente? a la de ¿qué hace la gente con los medios?, el paso de la visión de la transmisión de información a la de la dialógica interactiva que informa y se transforma parece ser una base amplia de la construcción de una nueva estructura del conocimiento que no sólo abarca a los estudios de la comunicación, sino a la estructura del conocimiento amplio, incluyendo a las ciencias sociales" (GOMÉZ, 2011: 117). de contestação dos valores apregoados pela modernidade. Emergiram estudos sobre cultura popular e de comunicação alternativa - fortemente relacionada aos pressupostos atribuídos aos estudos culturais.

em algum momento dentro dos estudos da comunicação aconteceu uma mudança, passando da pergunta "o que fazem os meios com as pessoas?" para "o que fazem as pessoas com os meios?, a passagem da visão da transmissão de informação para a da dialógica interativa que informa e transforma parece ser uma base ampla da construção de uma nova estrutura de conhecimento que não somente abarca os estudos de comunicação, como a toda a estrutura de conhecimento mais amplo, envolvendo as ciências sociais. (Ibid.: 117, tradução nossa) ${ }^{8}$

Na medida em que os estudos culturais não se propõem a ser uma disciplina curricular nos moldes tradicionais - com um campo de produção marcado por fronteiras limitadas -, suas produções podem ser compreendidas em alguns momentos como uma "teoria viajante". O fato de pesquisadores de diversos países terem se identificado com os estudos culturais não pode ser entendido, necessariamente, como uma imigração dos estudos culturais britânicos: "as conexões entre os estudos que revolucionam a teoria cultural contemporânea podem ser atribuídas, primordialmente, à amplitude e abrangência destas movimentações no cenário de um mundo que se torna transparente" (COSTA; SILVEIRA; SOMMER, 2003: 44).

Restepro (2015) destaca, ainda, que dentre as inúmeras preocupações desses estudos estão, especialmente, as temáticas indígenas, a formação de identidades na América Latina e o consumo cultural de produtos midiáticos, ou seja, os estudos de recepção. "Tanto uma como outra questão se confrontam na tensão global x local" (Ibid.: 48). O autor pontua a necessidade de pensar sobre os estudos culturais sempre como "contextuais e situados" e diz ainda que melhor seria nominar essa tradição como "Estudos Culturais sobre/desde a América Latina" (Ibid.: 28).

No que se refere aos estudos de recepção na região, Jesús Martín-Barbero é o pioneiro na reflexão sobre as relações entre comunicação e cultura, deslocando a centralidade da análise dos meios para os usos sociais produzidos pelos sujeitos (GOMES, 2004; JACKS, 2012). É a partir dos anos 1980 que a temática emerge como problemática. Além de Jesús Martín-Barbero, Nestor Garcia Canclini é considerado um dos expoentes nesse campo e, posteriormente, Guillermo Orozco Gomez. Entre as principais críticas recebidas pelos estudos culturais, além da possível importação de teorias, está a pouca atenção para temáticas de classe e o pouco engajamento político de alguns projetos.

\section{Possibilidades de diálogo}

Os estudos culturais e os estudos descoloniais emergem com a intenção de produzir uma ruptura nas discussões realizadas a respeito de culturas e povos subalternizados ao longo dos séculos. Com impactos em épocas distintas, provocaram (e provocam) inúmeras discussões em uma ciência que ainda é fortemente marcada pelo positivismo (e suas consequentes reivindicações de uma suposta neutralidade e universalidade, marcadas por um sistema-mundo capitalista, masculinista, racista, cis-heteronormativo e ocidentalista).

A ruptura produzida pelos estudos descoloniais é mais recente e atinge também os estudos culturais, ainda que inegavelmente tenham recebido contribuições desses. Com a proposta de romper com as formas de pensamento hegemônicas, ambas tradições são questionadas por seus procedimentos teóricos e metodológicos. Essas dificuldades podem ocorrer pela escolha em se desvincularem dos campos engessados das disciplinas formalmente instituídas, dialogando ainda com outras formas de saber, muitas vezes desconsideradas pela academia.

A crítica apresentada pelos estudos descoloniais aos estudos culturais, no que se refere à constituição de referenciais que continuam marcados pela modernidade, 
precisa ser considerada. Pensar a partir/desde a América Latina requer construir teorias que reflitam a partir desse lócus, um "lócus fraturado", como pontua Lugones (2016). Local marcado pela colonialidade, pela modernidade, pela persistência de subordinação. Para pensar nas margens é preciso afetar-se pelas margens.

Entretanto, como afirma Grosfoguel (2008: 117), essa não pode ser "uma crítica antieuropeia fundamentalista e essencialista". Ou seja, devemos aprofundar a necessidade de produzir um "pensamento de fronteira". Isso significa abandonar projetos epistemológicos ligados ao modernismo e aos pós-modernismos, "aprisionados no interior do cânone ocidental, reproduzindo, dentro dos seus domínios de pensamento e prática, uma determinada forma de colonialidade do poder/conhecimento" (Ibid.: 116) e pensar dentro de outros marcos.

A ruptura não é simples. Como pontua Ballestrin (2013), é possível abandonar toda a tradição de estudos produzidos (e legitimados ao longo dos séculos) pela/na Europa? O pensamento de "fronteiras" é também um pensamento de diálogo. Nesse sentido, compreende-se que, por suas próprias características fundantes, os estudos de recepção aproximam-se dos estudos descoloniais, refletindo sobre agenciamento e sobre o encontro de saberes e práticas dos sujeitos nas relações com as mídias, invertendo, desse modo, a preocupação dos meios para as audiências.

O debate sobre diferenças e possibilidades de aproximação entre estudos culturais e estudos descoloniais está aberto. Catherine Walsh (2003) concebe os estudos culturais latino-americanos como "(inter)culturais" e de orientação descolonial. Nas palavras da autora: "pensando a partir desta região, das lutas, práticas e processos que questionam os legados eurocêntricos, coloniais e imperiais e pretendem transformar e construir condições radicalmente distintas de pensar, conhecer, ser, estar e conviver" (Ibid.: 220-221).

Sem respostas absolutas e contundentes, acredita-se na possibilidade de construção de uma pesquisa de recepção de inspiração descolonial. A contribuição dos estudos descoloniais, compreendendo as marcas da colonialidade do poder e do saber sobre os sujeitos e instituições, pode ser articulada com as contribuições dos estudos culturais acerca da mídia - um dos espaços sobre os quais os estudos descoloniais ainda não se debruçaram.

\section{Referências}

BALLESTRIN, L. América Latina e o giro decolonial. Revista Brasileira de Ciência Política, Brasília, DF, n. 11, p. 89-117, ago. 2013. Disponível em: <https://goo.gl/ WdQjKt>. Acesso em: 28 nov. 2016.

COSTA, M. V.; SILVEIRA, R. H.; SOMMER, L. H. Estudos culturais, educação e pedagogia. Revista Brasileira de Educação, Rio de Janeiro, n. 23, p. 36-61, 2003. Disponível em: <https://goo.gl/6bBdps>. Acesso em: 12 dez. 2016.

ESCOSTEGUY, A. C. D. Cartografia dos estudos culturais: uma versão latino-americana. Belo Horizonte: Autêntica, 2010.

ESCOSTEGUY, A. C. D.; JACKS, N. Comunicação e recepção. São Paulo: Hacker Editores, 2005.

GOMES, I. M. M. Efeito e recepção: a interpretação do processo receptivo em duas tradições de investigação sobre os media. Rio de Janeiro: E-Papers Serviços Editoriais, 2004.

GÓMEZ, H. Cultura, comunicación y la estructuración del tiempo. In: CÁCERES, J. G.; GARCÍA, M. R. (Coord.). Comunicología posible: hacia una ciencia de la comunicación. Léon: Universidade Iberoamericana, 2011. p. 111-160. 
GROSFOGUEL, R. Para descolonizar os estudos de economia política e os estudos pós-coloniais: transmodernidade, pensamento de fronteira e colonialidade global. Revista Crítica de Ciências Sociais, Coimbra, n. 80, p. 115-147, mar. 2008.

HALL, S. Da diáspora: identidades e mediações culturais. 2. ed. Belo Horizonte: Editora UFMG, 2013.

JACKS, N.; MENEZES, D. Estudos de recepção no Brasil: um panorama da última década. In: ENCONTRO DA COMPÓS, 21., 2012, Juiz de Fora. Anais eletrônicos... Juiz de Fora: Compós. Disponível em: <https://goo.gl/Rjztvx>. Acesso em: 15 dez. 2016.

LISBOA, A. M. De América a Abya Yala - Semiótica da descolonização. Revista de Educação Pública, v. 23, n. 53/2, p. 501-531, 2014.

LUGONES, M. Rumo a um feminismo descolonial. Revista Estudos Feministas, Florianópolis, v. 22, n. 3, p. 935-952, set./dez. 2014. Disponível em: <https://goo. gl/2wc6DG>. Acesso em: 11 ago. 2016.

MARTíN-BARBERO, J. Nosotros habíamos hecho estudios culturales mucho antes de que esta etiqueta apareciera. Entrevista a Jesús Martín-Barbero. Dissens, Berlín, n. 3, p. 47-53, 1996.

MIGNOLO, W. Posoccidentalismo: el argumento desde América Latina. Cuadernos Americanos: Nueva Época, Cidade del México, v. 1, n. 67, p. 143-165, jan./fev. 1998.

Introduction. Coloniality of power and decolonial thinking. Cultural Studies, v. 21, n. 2-3, p. 155-167, mar./maio 2007.

RESTEPRO, E. Sobre os estudos culturais na América Latina. Revista Educação, Porto Alegre, v. 38, n. 1, p. 21-31, jan./abr. 2015.

REYNOSO, C. Apogeo y decadencia de los estudios culturales: una visión antropológica. Barcelona: Gedisa, 2000.

WALSH, C. ¿Qué saber, qué hacer y cómo ver? Los desafíos y predicamentos disciplinares, políticos y éticos de los estudios (inter)culturales desde América Andina. In:__. (Comp.). Estudios culturales latinoamericanos: retos desde y sobre la región Andina. Quito: Universidad Andina Simón Bolívar; Abya Yala, 2003. p. 11-28. 